\title{
Helminthiasis Prevalence Based on GIS along Thai-Cambodian Border in Phusing District, Sisaket Province,Thailand
}

\author{
Soncharoen, P., ${ }^{1,3}$ Thanasai, J., ${ }^{1,3}$ Kamtoom, W. ${ }^{1,2}$ Chuenkomol, S., ${ }^{2}$ Zito Viegas Da ${ }^{1,2}$ and Nithikathkul, \\ C. ${ }^{1,3^{*}}$ \\ ${ }^{1}$ Tropical and Parasitic Diseases Research Unit, Faculty of Medicine, Mahasarakham University, Thailand \\ E-mail: nithikethkul2016@gmail.com \\ ${ }^{2}$ Tropical Health Innovation, Faculty of Medicine, Mahasarakham University, Thailand \\ ${ }^{3}$ Health Science program, Faculty of Medicine, Mahasarakham University, Thailand \\ ${ }^{*}$ Corresponding author
}

DOI: https://doi.org/10.52939/ijg.v17i5.2021

\begin{abstract}
Helminthiasis has been a major public health problem in Southeast Asia, especially in rural areas significant along the Thai national borderline. This research within provincial public health working standard aimed to identify the situation and influent factors along 3 sequential purposes within 3 steps as 1)To explore 5 years situation to get the specific study area, 2)To find out the prevalence of the area, and 3)To excrete the influent factors. The target area of the first step comprised 2 subdistricts, Donrak and Phrai Phattana within 9873 parents who participated in the stool examination program in 2015-2019 under the provincial Public Health Office, of primary school pupils. In the second step specific area were selected via the criteria of 30 percentile of the high border length line which were 2 subdistricts. 469 parents in those did re-examine their stool in the last 3 months in 2019 to compare the 2 sets of the prevalence. In both steps of the analysis, basic data were gender and 6 age ranges (Min $=20$ years old, Max $>60$ years old).In the final step, influent factors based on the documents and congruence among 6 responsible staffs with an equal number in each. The stool examination was FECT and helminthiasis simple smear in the first 2 steps was in the same standard. In the third one, the excreted factors were supported by theories and 100 percent of the congruence. The results were as 1)In the first step, $15.96 \%$ among 9873 subjects were infected. Male (n=893)was statistically significant higher $(P<=.05)$ than female $(n=682)$. The age range mode was 41-50 years old. 2$)$ In the second step, $21 \%$ among 496 subjects were infected. Male $(n=37)$ was statistically significant higher than female $(n=13)$ at .05 level. Age range mode was in 40-50 years old in both subdistricts. 3)In the final step, 3 influent factors were delivered out as the number of water resources and geographical patient location, and fish consuming behavior. The beyond results besides the purposes revealed prevalence of helminthiasis comprised; Opisthorchis viverrini(47.08\%), hookworm(28.17\%), and Taenia spp(6.91\%). This was crucial for further investigation in each type to be able to link into both the public health and helminth professional area.
\end{abstract}

\section{Introduction}

Helminthiasis infection remains a major public health problem. The worldwide estimation by WHO in 2021 was 1.5 billion people or $24 \%$ was affected, and mostly found in developing countries in ASEAN (Hotez et al., 2007). Especially in tropical wet ones. Estimation in ASEAN was over 5.3 billion people were at risk of infections (Escobedo et al., 2008). Moreover, at least one type of Helminth infection was found (Darlan et al., 2019) in Thailand, the infection was high, especially in rural areas. The parasitic infection problems including spreading are continuously continued across all regions of Thailand (Jongsuksuntigul and Imsomboon, 2003) with the variation prevalence among kinds of helminthiasis in different regions. The Northeastern was mainly founded in the liver fluke, while hookworms, earthworms and whipworms were referenced in the South (Anantaphruti et al., 2000). The most common soiltransmitted helminth is earthworms (Ascaris lumbricoides), hookworms (Necartor americanus and Ancylostoma spp.), and whipworm (Trichuris trichiura) (Bundy, 1990). The endemic around 120 countries approximate $770-890$ million cases of 
ascariasis, while 430-500 million were trichuriasis and 410-480 million were hookworm infected (Acka et al., 2010). Most infections are high incidence in the nearby forest area which are mostly rural ones. They are at high risk such as; living in the border, especially border boundary with lower education, inaccessible technology, unhygienic lifestyle behavior sanitation, and low income. These widen doors to helminth infections. Support findings in different regions with significantly different percentages of types of helminthiasis prevalence above claims the relation between Geographic information system(GIS) and such infection as a risk factor.

Causes and risk in helminth infections factors, according to literature reviews, there were many factors include; 1)personal factors (Acka et al., 2010, Darlan et al., 2019, Escobedo et al., 2008, Shang et al., 2010 and Wang et al., 2012), 2)family factors (Ahmed et al., 2011, Darlan et al., 2019, Escobedo et al., 2008, Gunawardena et al., 2011, Nasr et al., 2013 and Ziegelbauer et al., 2012), 3)economic and social factors (Bath et al., 2010, Kounnavong et al., 2011 and Yajima et al., 2009), 4)environmental factors (Kattula et al., 2014) and 5)geographical factors. So, this study was finding out the risk factors of helminth infections. There were focus on factors and risk group in the community and sources of water and household, environment (Darlan et al., 2019 and Escobedo et al., 2008). In the same time, there have been a total of 230 million school-age children cases of helminth infections. There were included 125 million Ascariasis infections, 90 million Trichuriasis infections, and 20 million hookworm infections (World Health Organization, 2011). As mentioned, the evidence indicates that should be studied the situations and pathogenic factors of soil-transmitted helminths school-age children to be used as data for planning the prevention of soil-transmitted helminths in this group. In addition to the study in school-age children, also need to study their parents because the children are still unable to take care of themselves and must be in the care of their parents and living in the same environment. GIS and sensitive target group of primary school pupils are important and the surveillance can be run through their parents.

Parents of school-age children, especially mothers who are closed, and raising their child up, be influential persons, and role models to mimic the children's behavior. Several studies showed that education and the practice of parents impact on their children associated with soil-transmitted helminth infections. According to the study the knowledge, attitudes, and behaviors of children's parents were founded that there were inappropriate knowledge, attitudes, and behaviors, at risk of soil-transmitted helminth infections. (Acka et al., 2010, Belyhun et al., 2010, Shang et al., 2010 and Wang et al., 2012). Such children infection impacts to learning effectiveness yielding from their insufficient nutrients including the slow down their development and their maximum potential in many aspects comparable with other children (World Health Organization, 2009). Parents' helminthiasis infection surveillance is important with signification to their children based on their primary school GIS.

This study was run through Phu Sing District, Sisaket Province. These areas are located in northeastern Thailand. It was culturally diverse and comprising many ethnicities in Thai, Laos, Khmer, and Soih. There lived on the Thai-Cambodian border and Chong Sang Ngam Border Crossing. That was the opportunity for immigration and smuggling into the work of many foreign workers. These factors affect the prevention and control of communicable diseases as well. Finally, this study demonstrated and monitor public health and family health issues, which will advantage the public health sectors to control and planning for preventing helminths infection

\section{Materials and methods}

\subsection{Research Design}

Mixed methods designed was applied into 3 sequential steps as follows: 1)To find out its average prevalence situation in a target responsible area, 2) To compare it with the higher prevalence of specific area according to find out influent factors and 3)To verify findings based on the sequential relevance of on the laboratory results, theoretical supports, and responsible staffs congruences.

\subsection{Research Tools and Data Collection}

Research Tools: In the first two steps, the laboratory frame comprised formalin-ethyl acetate concentration technique (FECT) and simple direct smear within the solid provincial public health office standard. An instrument for estimating the prevalence of helminth eggs, filaria by chemicals used for fecal examination by the Formalin ether concentration technique (FECT).

First, the researcher sent a letter to the Provincial Health office and Phu Sing District Health Office requesting permission to use the information of this area. Second, a health professional in Phu Sing District has performed stool examination by using the Formalin ether concentration technique (FECT). The procedure is as follows; (1) take 1 gram of feces into a $50 \mathrm{ml}$ Bigger, add $10 \mathrm{ml}$ Normal Saline, and then mix. (2) filtered through 2 layers of gauze into 
a plastic tube with a pointed bottom of $15 \mathrm{ml}$. (3) centrifuged with a speed of 2000-2500 rpm for 5 minutes. (4) pour the top liquid that was left with only used the bottom sediment, then add $3 \mathrm{ml}$ of ether and $7 \mathrm{ml}$ of $10 \%$ formalin, and shake well. (5) centrifuged at $2000 \mathrm{rpm}$ for 5 minutes, resulting in a solution that is separated into 4 layers, the upper layer includes ether, fat, formalin, and sediment containing helminth eggs. (6) use a stick to pierce the fat layer around the plastic tube and pour the solution out, then add the remaining sludge to the 1$2 \mathrm{ml}$ volume of $10 \%$ formalin and mix well. (7) use a Pasteur Pipette to suck up the mixed solution and examine it under a microscope for helminth eggs. Analyze the prevalence rate of helminths calculated using the formula: General data checklist was applied as a form before the examination. While 25 high related papers and in-depth interviews were focused on the third step.

\subsection{Data Collection}

The frame of the target area and the subjects for data collection were followed with the three research steps as follows:

1)In the first step, the target area was Phusing district, Sisaket province, Thailand which comprised 7 sub-districts. The subjects were primary school pupils'parents who participated in the stool examination program under the provincial public health office in the year 2015-2019.

2)In the second step, two subdistricts, Dongrak and Phraipattana, were purposively selected under the criteria of the 30 percentile of high borderline length among the above 7 subdistricts. The subjects were primary school pupils' parents who had participated in a stool examination program in the first step they were rechecked stool examination the last 3 months in 2019.

3)In the third step, the verification was based on supports among 25 high related references and 100 percentage among 6 responsible staff which has an equal number in each of the two specific subdistricts.

\subsection{Data Analysis}

According to GIS, The geographical information using Arc GIS for demonstration and evaluation. There was established the prevalence of infection in Dong Rak Subdistrict and Phrai Phatthana Subdistrict, Phu Sing District, Sisaket Province in Thailand, a spatial inverse distance estimation (IDW) technique was used in the ArcGIS program to generate a predicted prevalence map. Preservation of the spatial pattern of helminth infections (software ArcGIS 10.8 (ESRI, Redlands CA).

According to general data and laboratory results, the statistical data analysis was performed by computer packaging program SPSS version 25 for descriptive statistics include frequency distribution, percentage, mean and standard deviation. Moreover, an independent t-test was applied. This research has been approved by the Human Research Ethics Committee of Mahasarakham University. (Approval No.146/2020) and the subjects themselves completed the University standard consent form before the start of data collection.

\section{Results}

The results of patient's characteristics data who attended the public health service, in Phusing District, Sisaket Sisaket Province from January 2015 to December 2019. The 9,873 stool samples were collected and examined for parasitic infections with formalin-ethyl acetate concentration technique (FECT) and/or simple direct smear. The result showed the infections were found in 1,576 cases $(15.96 \%)$ with 889 males $(56.04 \%)$ and 687 females $(43.59 \%)$. The prevalence of helminth infections is associated with gender and age which presented a high helminthic infections rate in males. The prevalence of helminth infections was different for each age $(p<0.01)$, with the highest prevalence of helminths, ranged in the 42 years $(12.2 \%)$ and the lowest prevalence found in two groups of age that lower than 30 years and over 61 years $(0.20 \%)$.

The majority of helminth infections were found in the top 3 highest composed of Opisthorchis viverrini, hookworm, and Taenia spp. Firstly, the Opisthorchis viverrine infection showed $46.13 \%$ and $48.38 \%$, in males and females respectively. When considering the Opisthorchis viverrine infection in each age group, the highest was found in the age range $41-50$ years $47.70 \%$, followed by age group 31-40 years, $37.20 \%$, and age group over 50 years 8.50 percent, respectively.

Secondly, for hookworm infection, males and females were found $65.09 \%$ and $34.90 \%$, respectively. The highest hookworm infection was found in the age range $41-50$ years by $46.60 \%$, followed by aged $31-40$ years by $33.70 \%$ and the group aged over 50 years by $9.00 \%$, respectively. Thirdly, Taenia spp. infections, males and females were found the highest prevalence of Taenia spp. infection by $58.74 \%$ and $41.28 \%$, respectively. The highest Taenia spp. infections were found in the age range $41-50$ years by $44.00 \%$, followed by the group aged $31-40$ years by $42.20 \%$ and the group aged over 50 years by $5.50 \%$, respectively. The detail shows in Table 1 and Figures 1-5. 
According to the study of helminth infections among parents who live in the Thai-Cambodian border in two sub-districts in Phusing District consists of Dongrak Subdistrict and Phrai Phattana
Subdistricts, in 2019 during January to December, in Dong Rak Subdistrict a total infection was 496 cases, 21 cases were infected $4.23 \%$ with 16 males (76.19\%), 5 females $(23.80 \%)$.

Table 1: The situation of infection with various types of helminths in Phusing District from January 2015 to December 2019

\begin{tabular}{lccccccccc}
\hline $\begin{array}{c}\text { Type of } \\
\text { helminths }\end{array}$ & \multicolumn{1}{c}{ Total } & \multicolumn{3}{c}{ Infection by gender } & \multicolumn{5}{c}{$\begin{array}{c}\text { Infection by age group (year) } \\
\text { Number (percent) }\end{array}$} \\
\hline & & Male & Female & $\leq 20$ & $21-30$ & $31-40$ & $41-50$ & $51-60$ & $>61$ \\
\hline Total number & 1,575 & 893 & 682 & 0 & 115 & 577 & 732 & 133 & 19 \\
of samples & $(13.47)$ & $(56.69)$ & $(43.30)$ & $(0.00)$ & $(7.30)$ & $(36.60)$ & $(46.40)$ & $(8.40)$ & $(1.20)$ \\
\hline Opisthorchis & 742 & 412 & 330 & 0 & 49 & 314 & 402 & 72 & 6 \\
viverrini & $(47.11)$ & $(55.52)$ & $(44.47)$ & $(0.00)$ & $(5.80)$ & $(37.2)$ & $(47.70)$ & $(8.50)$ & $(0.70)$ \\
\hline Taenia spp. & 109 & 64 & 45 & 0 & 9 & 46 & 48 & 6 & 0 \\
& $(6.92)$ & $(58.74)$ & $(41.28)$ & $(0.00)$ & $(8.30)$ & $(42.2)$ & $(44.0)$ & $(5.50)$ & $(0.00)$ \\
\hline Hookworm & 444 & 289 & 155 & 0 & 39 & 149 & 206 & 40 & 8 \\
& $(28.19)$ & $(65.09)$ & $(34.90)$ & $(0.00)$ & $(8.80)$ & $(33.70)$ & $(46.60)$ & $(9.00)$ & $(1.90)$ \\
\hline Ascariasis & 26 & 19 & 7 & 0 & 1 & 10 & 14 & 1 & 0 \\
& $(1.65)$ & $(73.07)$ & $(26.92)$ & $(0.00)$ & $(3.80)$ & $(38.50)$ & $(53.80)$ & $(3.80)$ & $(0.00)$ \\
\hline Trichuris & 0 & 0 & 0 & 0 & 0 & 0 & 2 & 1 & 0 \\
trichiura & $(0.00)$ & $(0.00)$ & $(0.00)$ & $(0.00)$ & $(0.00)$ & $(0.00)$ & $(66.70)$ & $(33.30)$ & $(0.00)$ \\
\hline Strongyloides & 2 & 2 & 0 & 0 & 0 & 0 & 0 & 0 & 0 \\
stercoralis & $(0.12)$ & $(100.00)$ & $(0.00)$ & $(0.00)$ & $(0.00)$ & $(0.00)$ & $(0.00)$ & $(0.00)$ & $(0.00)$ \\
\hline Enterobiasis & 7 & 4 & 3 & 0 & 0 & 2 & 4 & 1 & 0 \\
& $(0.44)$ & $(57.14)$ & $(42.85)$ & $(0.00)$ & $(0.00)$ & $(28.60)$ & $(57.10)$ & $(14.30)$ & $(0.00)$ \\
\hline Other & 245 & 103 & 142 & 0 & 17 & 56 & 56 & 12 & 5 \\
parasites & $(15.55)$ & $(42.04)$ & $(57.95)$ & $(0.00)$ & $(11.60)$ & $(38.40)$ & $(38.40)$ & $(8.20)$ & $(3.40)$ \\
\hline
\end{tabular}

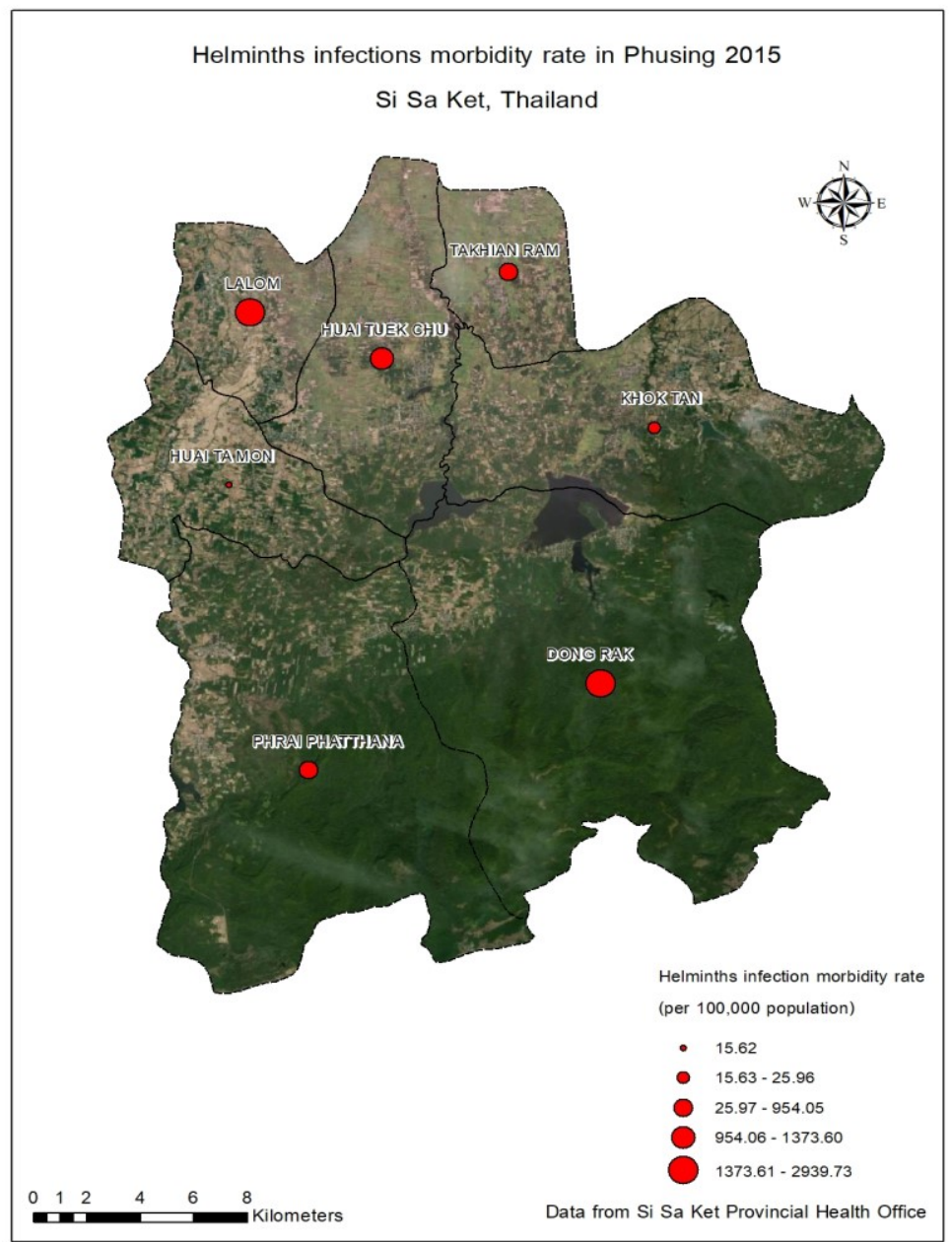

Figure 1: The Geographic information of infection with various types of helminths in Phusing District, 2015 


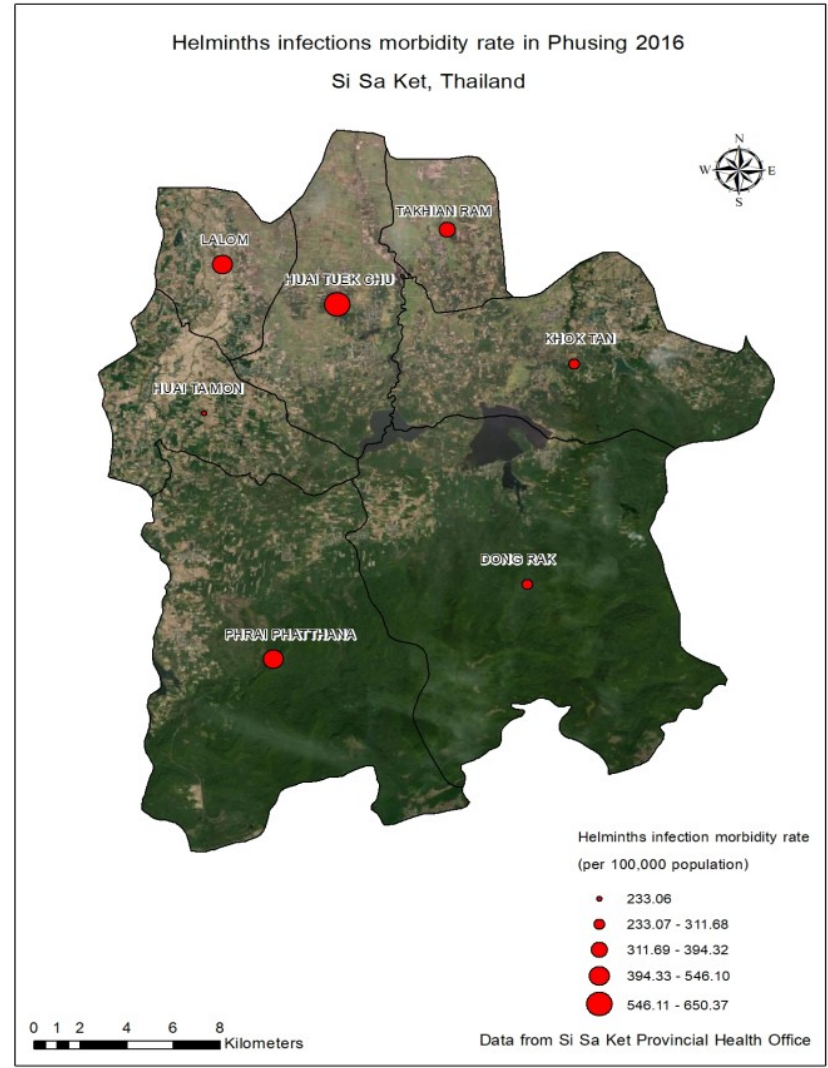

Figure 2: The Geographic information of infection with various types of helminths in Phusing District, 2016

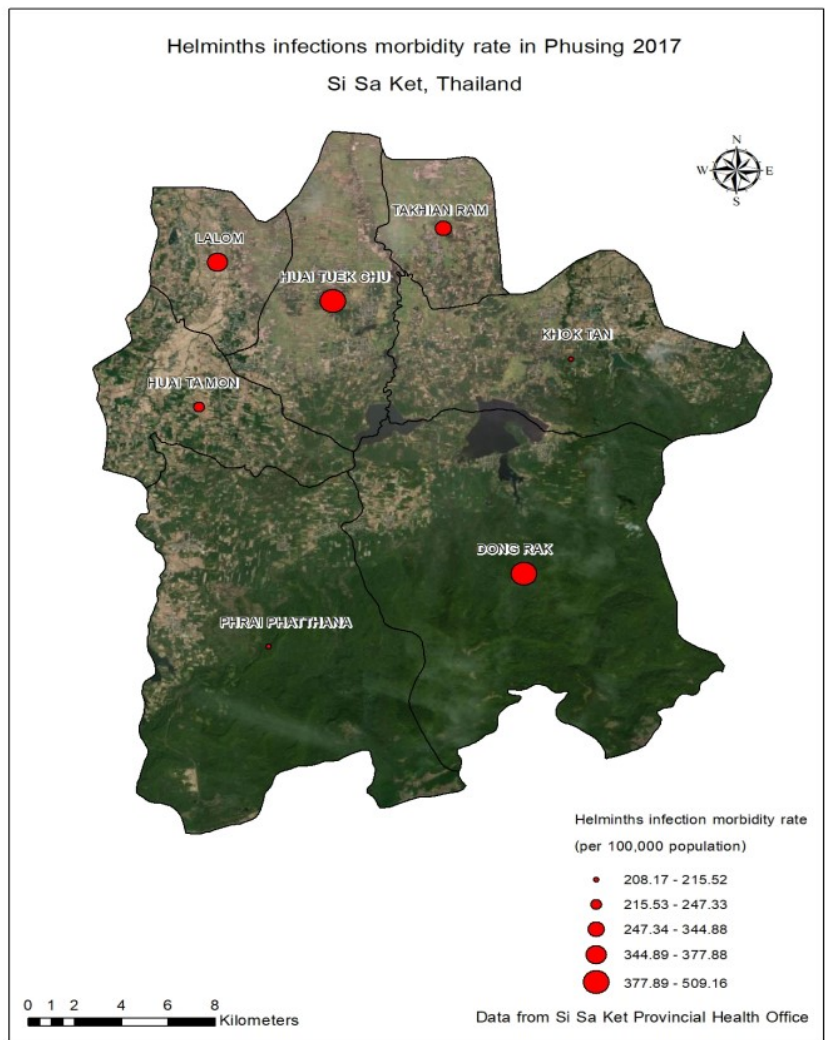

Figure 3: The Geographic information of infection with various types of helminths in Phusing District, 2017 International Journal of Geoinformatics, Vol. 17, No. 5, October 2021 


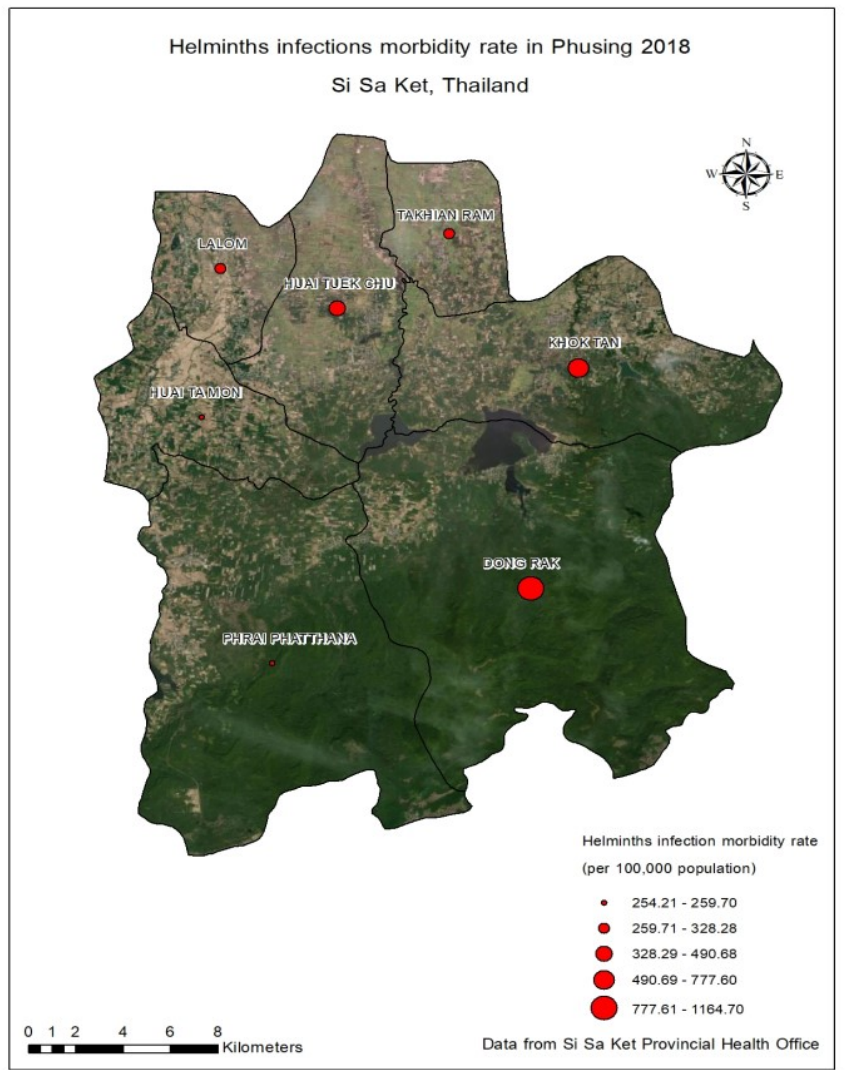

Figure 4: The Geographic information of infection with various types of helminths in Phusing District, 2018

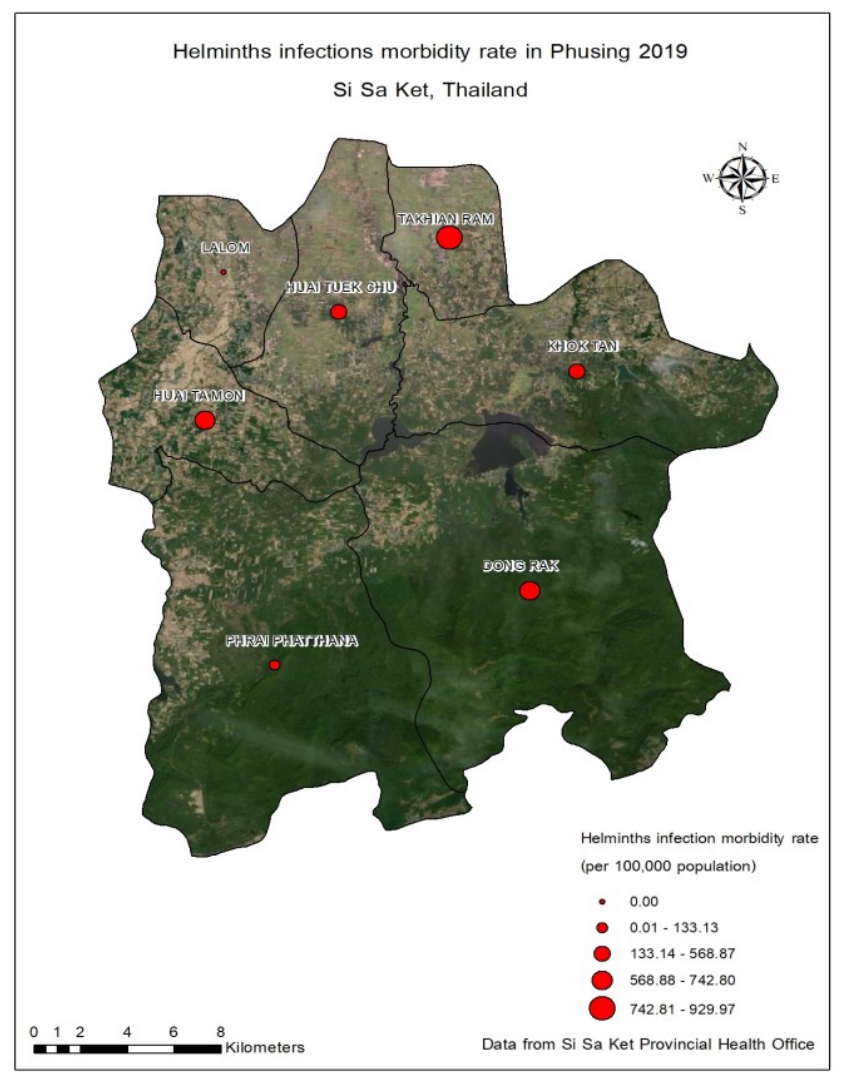

Figure 5: The Geographic information of infection with various types of helminths in Phusing District, 2019 International Journal of Geoinformatics, Vol. 17, No. 5, October 2021 
The prevalence of helminth infections was associated with sex and age which presented a high helminthic infection rate in males. The prevalence of helminth infections was different for each age ( $p$ $<0.01$ ), with the highest prevalence of helminths, ranged in age $35(23.8 \%)$ and the lowest found in the lower age range and over 30 years $(14.30 \%)$.

The result of the situation of infection with various types of helminths was found in the top 3 highest composed of Opisthorchis viverrini, hookworm, and Taenia spp. Firstly, Opisthorchis viverrini infection found males and females had the highest prevalence by $78.51 \%$ and $21.42 \%$, respectively. When considering the Opisthorchis viverrini infection in each age group, the highest Opisthorchis viverrini infection was found in the age range $41-50$ years and 31-40 years, followed by $51-60$ years by $21.40 \%, 21.30 \%$, and $7.10 \%$ respectively. Secondly, for hookworm infection, males and females were found the highest prevalence of hookworm infection by $60.00 \%$ and $40.00 \%$, respectively. When considering the hookworm infection in each age group, the highest hookworm infection was found in the age range 4150 years by $80.00 \%$, followed by $51-60$ years by $20.00 \%$ respectively.

Thirdly, Taenia spp. infection, males were found the highest prevalence of Taenia spp. infections by $100 \%$. When considering Taenia spp. infection in each age group, the highest Taenia spp. infection was found in the age range 51-60 years by $100 \%$, including the highest prevalence of Ascaris lumbricoides infection by $100 \%$. When considering the Taenia spp. infection in each age group, the highest Ascaris lumbricoides infection was found in the age range $41-50$ years by $100 \%$ (Table 2). According to helminthiasis in Phrai Phattana Subdistrict was conducted data from January 2019 to December 2019. At the same time, Phrai Phatthana sub-district examined a total of 496 cases. It was found that 29 cases $(5.84 \%)$ were infected, consisting of males. 21 cases $(72.41 \%), 8$ women $(27.58 \%)$. From chi-squared statistics analysis ( $p$ $<0.05$ ), found that the prevalence of helminth infections was associated with sex and age. There was shown a high helminthic infection rate in males. Moreover, the prevalence of helminth infections was different for each age group $(p<0.01)$, with the highest prevalence of helminths, $41.37 \%$ in age 42 50 years and the lowest prevalence found in 21-30 years and $3.40 \%$ for over 61 years

The result of the situation of infection with various types of helminths was found in the top 3 highest composed of Opisthorchis viverrini, hookworm, and Taenia spp. Firstly, Opisthorchis viverrini infection was found male and female had the highest prevalence by $75.00 \%$ and $25.00 \%$, respectively. When considering the Opisthorchis viverrini infection in each age group, the highest Opisthorchis viverrini infection was found in the age range $41-50$ years and 51-60 years by $31.30 \%$, followed by the age range $21-30$ years by $6.30 \%$ respectively. Secondly, hookworm infections, males, and females were found the highest prevalence of hookworm infection by $75.00 \%$ and $25.00 \%$, respectively. When considering the hookworm infection in each age group, the highest hookworm infection was found in the age range lower or equal 21-30 years, 31-40 years, 41-50 years, 51-60 years by $30.00 \%$. Thirdly, Taenia spp. infections, females were found the highest prevalence of Taenia spp. infection by $100 \%$. When considering the Taenia spp. infection in each age group, the highest Taenia spp. infection was found in the age range of 51.60 years by $100 \%$ (Table 3 ) and (Figure 6).

Table 2: The situation of infection with various types of helminths in Dongrak Subdistrict, Phusing District, from January 2019 to December 2019

\begin{tabular}{lccccccccc}
\hline \multicolumn{1}{c}{$\begin{array}{c}\text { Type of } \\
\text { helminths }\end{array}$} & \multicolumn{1}{c}{ Total } & \multicolumn{3}{c}{ Infection by gender } & \multicolumn{5}{c}{$\begin{array}{c}\text { Infection by age group (year) } \\
\text { Number (percent) }\end{array}$} \\
\hline & & Male & Female & $\leq 20$ & $21-30$ & $31-40$ & $41-50$ & $51-60$ & $>61$ \\
\hline $\begin{array}{l}\text { Total number } \\
\text { of samples } \\
\text { (S. Dongrak) }\end{array}$ & 21 & 16 & 5 & 0 & 3 & 10 & 8 & 0 & 0 \\
\hline $\begin{array}{l}\text { Opisthorchis } \\
\text { viverrini }\end{array}$ & 14 & 11 & 3 & 0 & 3 & 3 & 3 & 3 & 0 \\
\hline Taenia spp. & 1 & $(76.19)$ & $(23.80)$ & $(0.00)$ & $(14.28)$ & $(47.61)$ & $(38.09)$ & $0.00)$ & $(0.00)$ \\
& $(4.76)$ & $(100.00)$ & $(0.00)$ & $(0.00)$ & $(0.00)$ & $(0.00)$ & $(0.00)$ & $(100.00)$ & $(0.00)$ \\
\hline Hookworm & 5 & 3 & 2 & 0 & 0 & 4 & 1 & 0 & 0 \\
& $(23.80)$ & $(60.00)$ & $(40.00)$ & $(0.00)$ & $(0.00)$ & $(80.00)$ & $(20.00)$ & $(0.00)$ & $(0.00)$ \\
\hline Ascariasis & 1 & 1 & 0 & 0 & 0 & 0 & 1 & 0 & 0 \\
& $(4.76)$ & $(100.00)$ & $(0.00)$ & $(0.00)$ & $(0.00)$ & $(0.00)$ & $(100.0)$ & $(0.00)$ & $(0.00)$ \\
\hline
\end{tabular}


Table 3: The situation of infection with various types of helminths in Phrai Phattana Subdistrict, Phusing District, Sisaket from 2019 to December 2019

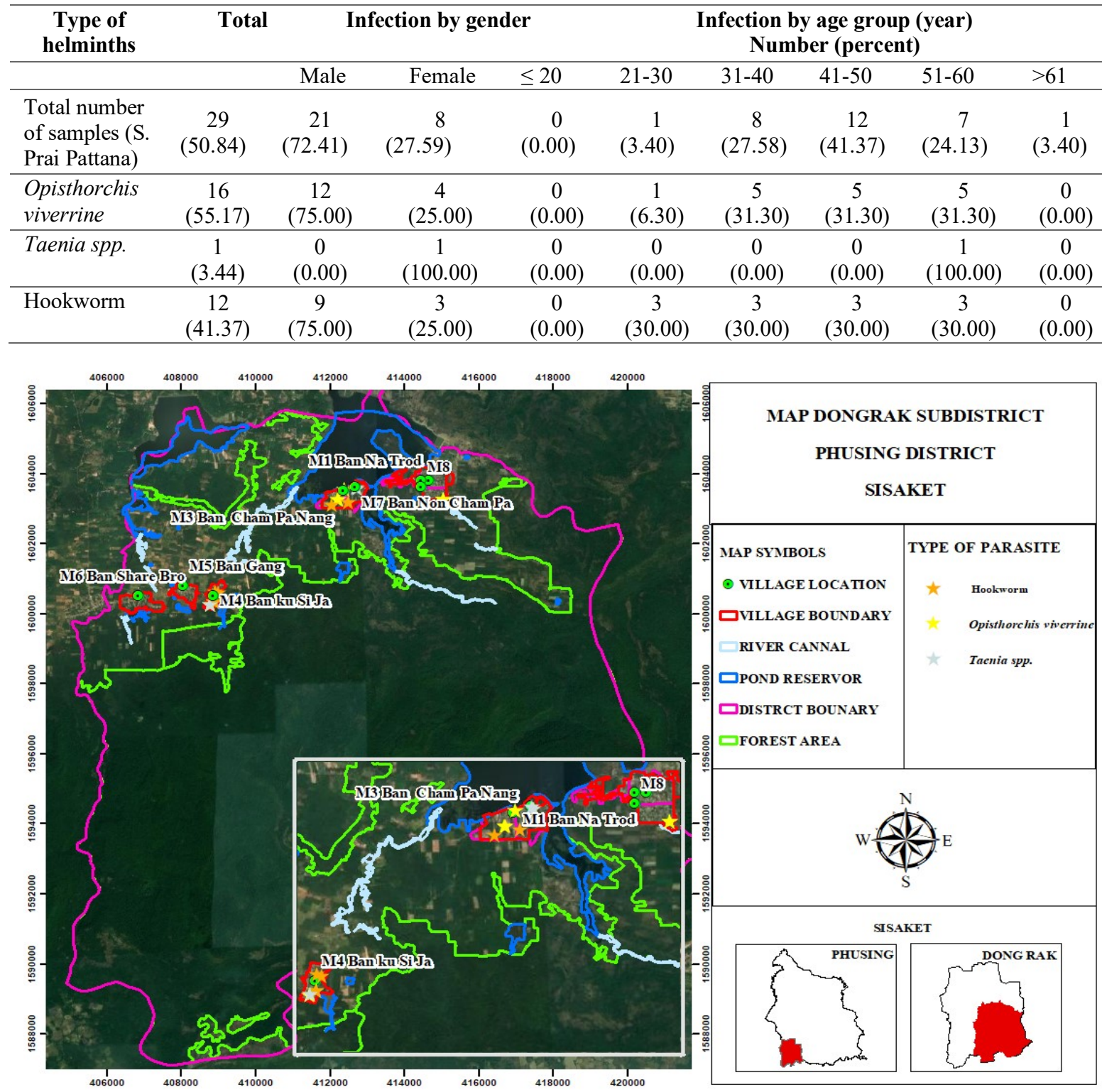

Figure 6: Map showing the district boundary, water sources, and forest areas of Dongrak Subdistrict, Phusing District, Sisaket Province

According to the study of helminth infections among parents who live in the $\mathrm{T}$ hai-Cambodian border in two sub-districts in Phusing District which were Dongrak Subdistrict and Phrai Phattana Subdistrict, from January 2019 to December 2019. In Dongrak Subdistrict was found a total infection of 21 cases. The highest helminth infection is composed of Opisthorchis viverrini, hookworm, and Taenia spp. respectively with 14 cases by $66.66 \%, 5$ causes by $23.80 \%$, and 1 case by $4.76 \%$ respectively. In Phrai Phattana Subdistrict was found a total infection was 29 cases.

The highest helminth infection is composed of Opisthorchis viverrini, hookworm, and Taenia spp. with 16 cases by $55.17 \%, 12$ causes by $41.37 \%$, and 1 case by $3.44 \%$ respectively. As a result, the top 3 highest infections of these two sub-districts are composed of Opisthorchis viverrini, hookworm, and Taenia spp. Most of the parasitic infection is caused by consumption behavior, followed by practice behavior. According to a survey of the surrounding 
areas of the two subdistricts, it can be seen that the surrounding areas of these two sub-districts are mostly connecting with almost 15 water sources. The nearest distance from the village to the water source is only 50 meters and far away only 2 kilometers.

According to visited the area to interview and explore the area around these two sub-districts, found that most people find fish for cooking in their family, and if they could find much fish, then it will be sold in the village. Moreover, people like to consume raw food for the whole family. So that, it related to helminth infections in people because there are a large number of liver fluke infections when compared with other parasitic infections and compared from the map showing the district boundary, water sources, and forest areas of Dongrak Subdistrict as Figure 2 and in Phrai Phattana Subdistrict, map showing the district boundary, water sources and forest areas as Figure 7. The above results were synthesized following the 3 main research purposes as 1)In the first step, $15.96 \%$ among 9873 subjects were infected. Male $(\mathrm{n}=893)$ was statistically significant higher $(\mathrm{P}<=.05)$ than female $(\mathrm{n}=682)$. The age range mode was $41-50$ years old. 2)In the second step, $21 \%$ among 469 subjects were infected. Male $(n=37)$ was statistically significant higher than female $(\mathrm{n}=13)$ at .05 level .Age range mode was in 40-50 years old in both subdistricts. 3)In the final step, 3 influent factors were delivered out as the number of water resources as well as geographical patient location, family functioning, and fish consuming behavior.

The beyond results besides the purposes revealed prevalence of helminthiasis comprised; Opisthorchisviverrini(47.08\%), hookworm(28.17\%), and Taenia spp(6.91\%). This was crucial for further investigation in each type to be able to link into both the public health and helminth professional area.

\section{Discussion}

1)In the first step, $15.96 \%$ among 9873 subjects were infected. Male ( $\mathrm{n}=893)$ was statistically significant higher $(\mathrm{P}<=.05)$ than female $(\mathrm{n}=682)$. The age range mode was 41-50 years old. The major factors that caused an at-risk soil-transmitted helminth infection included personal factors of gender, educational level, knowledge, attitudes, and behaviors such as not washing hands before eating and defecating. (Belyhun et al., 2010, Darlan et al., 2019, Escobedo et al., 2008, Nasr et al., 2013, Shang et al., 2010 and Wang et al., 2012). Relevantly to the findings on the gender of some scholars. Wang et al., (2021) founded that gender was effect with $75.6 \%$ of males consuming raw fish salad compared with $42.7 \%$ of females while Jin et al., (2021) stated that male was a significant risk factor for hookworm infection. The hookworm was more prevalent in males $(71.1 \%)$ than in females $(55.4 \%)(\mathrm{P}=0.022)$.

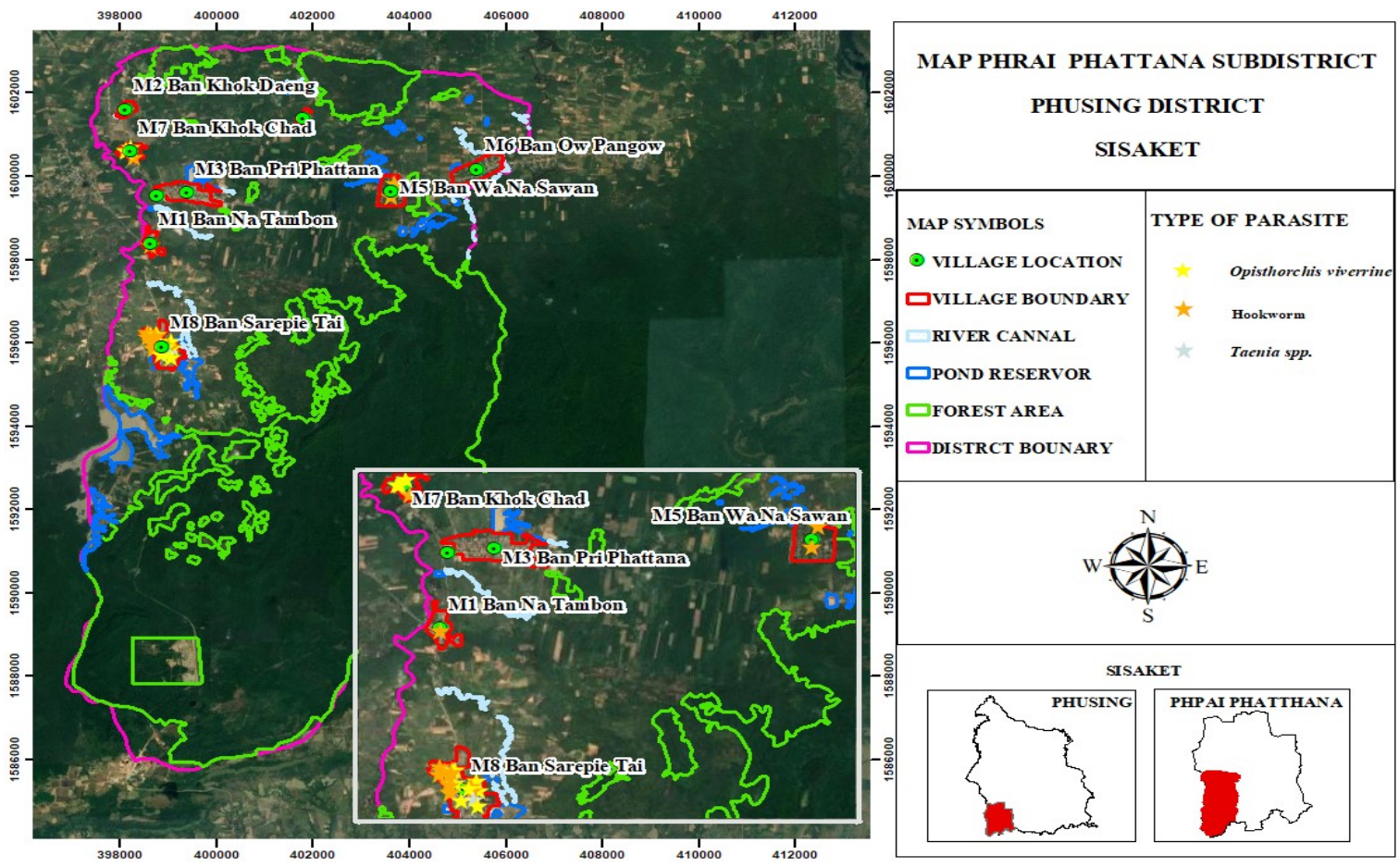

Figure 7: Map showing the district boundary, water sources, and forest areas of Phrai Phattana Subdistrict, Phusing District, Sisaket 
There was a risk of liver fluke and the risk of infection remain. At the same time, Thinkhamrop et al., (2020) founded that the most prevalence of hepatobiliary abnormality in males. There was hepatobiliary abnormality prevalence in $38.7 \%$; highest in males aged $>60$ years $(39.8 \%)$. The related result in gender influence was found that men are better educated than women, older are more knowledgeable than younger, higher education levels are better educated, and those with higher incomes have better knowledge than those with low incomes. Multiple logistic regression analysis indicated that the educational level of the respondents was the most important factor that associated with knowledge, attitudes, and the practices about soil-transmitted infections which related to Karnkawinpong et al., (2010).

2)In the second step, $21 \%$ among 469 subjects were infected. Male $(\mathrm{n}=37)$ was statistically significant higher than female $(\mathrm{n}=13)$ at .05 level. Age range mode was in $40-50$ years old in both subdistricts. In a rural area as a big family, the lower age range cannot act as an effective family leader as they have the next family elderly while the higher one delines family effective role and allow more family relaxation. The demonstration of knowledge, attitudes, and practices to prevent parasitics of the family's leader in Western Cote d' Ivoire found that the family's leader also has inappropriate knowledge and behavior (Acka et al., 2010). Therefore, it is recommended that health education should be provided to adult groups besides students (Belyhun et al., 2010) found that decreasing the risk of soil-transmitted helminth infections in mothers and their infants was associated with maternal hygiene. If mothers wash their hands regularly with soap and clean water, this can help decrease soiltransmitted helminth infections in mothers and their infants.

3) In the final step, 3 influent factors were delivered out as the number of water resources within the geographical patient location, family functioning, and fish consuming behavior.

3.1) related to GIS, the geographic information of helminthiasis in Phasing already showed high level and higher than National program level. The demonstration of helminthiasis and geographic information in the specific group will explain and showed a high level with the required special prevention and control program. Most of the infected were males by $56.69 \%$, which is related to the previous report. (Belyhun et al., 2010, Darlan et al., 2019, Escobedo et al., 2008, Nasr et al., 2013, Shang et al., 2010 and Wang et al., 2012). Ahmed et al., (2011) analyzed the factors affecting moderate to severe soil-transmitted helminth infections among people in rural Malaysia by using univariate statistics included using untreated water, living in a house without a latrine, and having pets in the house. When logistic regression analyzed found that drinking untreated water and no latrine in the house was a factor affecting moderate to severe soil-transmitted helminth infections as well as hill tribes (Thailand), the type of the latrines which are mostly septic toilet, also determining factor for being helminthiasis. Kawinphong (2010). Hence, environmental sanitation should be developed, especially the construction of a toilet, provided clean water, together with anthelmintic and health education to reduce the rate of soil-transmitted helminthiasis. Community factors, from the study of Yajima et al., (2008) found that soiltransmitted helminthiasis in Hoa Binh province, the high infection prevalence, despite high latrine coverage $(98.1 \%)$ in the study population. The presence of latrines alone is not sufficient to reduce the prevalence of helminthiasis in a rural agricultural community if fresh feces are used as fertilizer. Bath et al., (2010) found that having knowledge and awareness about intestinal worms but still have risk practices infected and intestinal worms infection, possibly due to socioeconomic and cultural conditions. Therefore, health education should be provided together with cultural and poverty solutions. Nasr et al., (2013) studied the factor that associated with soil-transmitted helminth infections among people in rural Malaysia was the absence of a toilet in the house and source for drinking water which related to Ziegelbauer et al., (2012) found that having latrines and using latrines was associated with prevention against three types of soil-transmitted helminth infections such as Ascaris lumbricoides, Trichuris trichiura, and hookworm.

3.2) Related to family functioning, in a specific group of Thai Cambodia border showed specific helminthiasis such as Opisthorchis viverrini, Hookworm, Taenia spp. which related with the reported of Department of Disease Control 2018 that the northeastern region, the infection rate was the highest in 
Nakhon Phanom Province by $41.90 \%$, followed by Sisaket Province by $39.70 \%$ of the parents were elementary level graduated and a little bit sample was graduated in secondary school. Moreover, most of them work in agriculture such as rubber plantations, raising animals, and farming. According to the studies shown that maternal education and occupation are important factors for the child's growth and development due to parents' lack of knowledge and awareness about helminthiasis prevention, both for themselves and their children. Besides, some families still practice such as eating raw food, etc. similar to Wang et al., (2012). The maternal education factor was shown associated with soil-transmitted helminth infections in preschool and schoolaged children in rural southwest China (Wang et al., 2012). Besides, Nasr et al., (2013) found that knowledge, attitudes, and behaviors related to soil-transmitted helminth infection related to household income in which the highincome family had better knowledge than the low-income family. The sanitation management system around the house is also an important factor in soil-transmitted helminth infections. Gunawardena et al., (2011) found that the schoolchildren in Sri Lanka in the plantation sector are still infected soil-transmitted, even after ten years of preventive chemotherapy because the environmental sanitation system in the house was poor, the important thing is that there are no latrines and clean water. Wang et al., (2012) and Nasr et al., (2013) found that families with 7 or more members were associated with soiltransmitted helminth infections. It was also found that knowledge, attitudes, and behaviors about soil-transmitted helminth infections were related to family size, with those living in larger families having better knowledge than those living in smaller families.

3.3) Related to consumer behavior, the schoolchildren in Sri Lanka in the plantation sector are still infected soil-transmitted, even after ten years of preventive chemotherapy because maternal education is still low (Gunawardena et al., 2011). As the study of parents' factors correlate with soil-transmitted helminth infections among people in rural Malaysia such as not washing hands before eating, and not washing hands after defecation Nasr et al., (2013). Also, a survey of the knowledge attitudes and behaviors of more than half of the respondents lack knowledge, attitudes, and behaviors about infections. These factors were related to age, sex, educational level, personal income were examined the determining factors of being helminthiasis in the hill tribes, Thailand. It was found that the health behavior factors influence on being helminthiasis in the hill tribes, Thailand such as 1) Consumption behavior is the consumption of raw or uncooked food with heat and contamination from drinking water. 2) Knowledge and attitudes about prevention and infection which the hill tribes still have inappropriate knowledge and negative attitude at some point 3) Hygiene, the importance is that washing hands and wearing shoes. The family factor is another factor that influences soil-transmitted helminth infections. It was found that the factor that was associated with soil-transmitted helminth infections in preschool and school-aged children in rural southwest China was the number of family members.

The beyond results besides the purposes revealed prevalence of helminthiasis comprised; Opisthorchis viverrini(47.08\%), hookworm(28.17\%), and Taenia spp(6.91\%). This was crucial for further investigation in each type to be able to link into both the public health and helminth professional area.

\section{Conclusion and Suggestion}

GIS focusing on water resources, gender, family functioning, mode of age range which may be related to some effective issues, and the rural area within the rural way of life can be as components for influent factors of helminthiasis infection. Each helminthiasis type and in total should be considered as independent variables to find out its influent factors in further studies. Plain informed data have to be considered for community awareness of the importance of prevention and control of helminth infections for more efficiency and sustainable news. The compile geographical demonstration will support the prevention regular treatment plan and suitable model for the specific group along the ThaiCambodian border.

\section{Acknowledgements}

The authors would like to thank for grants from Faculty of Medicine, Mahasarakham University and Sisaket Public Health Office. Special thanks for Phusing district officer, village volunteers and community for research collaboration. 


\section{References}

Acka, C. A., Raso, G., N'Goran, E. K., Tschannen, A. B., Bogoch, I. I., Séraphin, E. and Utzinger, J., 2010, Parasitic Worms: Knowledge, Attitudes, and Practices in Western Côte d'Ivoire with Implications for Integrated Control. PLOS Neglected Tropical Diseases, Vol. 4(12), doi:10.1371/journal.pntd.0000910.

Ahmed, A., Al-Mekhlafi, H. M., Azam, M. N., Ithoi, I., Al-Adhroey, A. H., Abdulsalam, A. M. and Surin, J. 2012, Soil-transmitted Helminthiasis: A Critical but Neglected Factor Influencing School Participation of Aboriginal Children in Rural Malaysia. Parasitology, Vol. 139(6), 802-808. doi:10.1017/S003118201100237X.

Ahmed, A., Al-Mekhlafi, H. M., Choy, S. H., Ithoi, I., Al-Adhroey, A. H., Abdulsalam, A. M. and Surin, J., 2011, The Burden of Moderate-toHeavy Soil-Transmitted Helminth Infections among Rural Malaysian Aborigines: An Urgent Need for an Integrated Control Programme. Parasites \& Vectors, Vol.4(1), 1-7.

Anantaphruti, M. T., Nuamtanong, S., Muennoo, C., Sanguankiat, S. and Pubampen, S., 2000, Strongyloides Stercoralis Infection and Chronological Changes of other SoilTransmitted Helminthiasis in an Endemic Area of Southern Thailand. Southeast Asian Journal of Tropical Medicine and Public Health, Vol. 31(2), 378-382.

Bath, J. L., Eneh, P. N., Bakken, A. J., Knox, M. E., Schiedt, M. D. and Campbell, J. M., 2010, Combating Evolving Pathogens: The Impact of Perception and Knowledge on the Treatment and Prevention of Intestinal Worms in the Manikganj district of Bangladesh. The Yale Journal of Biology and Medicine, Vol. 83(4), 171.

Belyhun, Y., Medhin, G., Amberbir, A., Erko, B., Hanlon, C., Alem, A. and Davey, G., 2010, Prevalence and Risk Factors for SoilTransmitted Helminth Infection in Mothers and their Infants in Butajira, Ethiopia: A Population Based Study. BMC Public Health, Vol. 10(1), 17.

Bundy, D. A., 1990, New Initiatives in the Control of Helminths. Trans R. Soc. Trop. Med. Hyg., Vol. 84(4), 467-468. doi:10.1016/00359203(90)90001-u.

Darlan, D., Winna, M., Simorangkir, H., Rozi, M., Arrasyid, N. and Panggabean, M., 2019, Soiltransmitted helminth and its Associated Risk Factors among School-Aged Children. IOP
Conference Series: Earth and Environmental Science,1-6, DOI:10.1088/1755-1315/305/1/012066.

Escobedo, A., Cañete, R. and Núñez, F., 2008, Prevalence, Risk Factors and Clinical Features Associated with Intestinal Parasitic Infections in Children from San Juan y Martínez, Pinar del Río, Cuba. West Indian Medical Journal, Vol. 57(4). 377-382.

Gunawardena, K., Kumarendran, B., Ebenezer, R., Gunasingha, M. S., Pathmeswaran, A. and de Silva, N. 2011, Soil-Transmitted Helminth Infections among Plantation Sector Schoolchildren in Sri Lanka: Prevalence after Ten Years of Preventive Chemotherapy. PLOS Neglected Tropical Diseases, Vol. 5(9), e1341. doi:10.1371/journal.pntd.0001341.

Hotez, P. J., Molyneux, D. H., Fenwick, A., Kumaresan, J., Sachs, S. E., Sachs, J. D. and Savioli, L., 2007, Control of Neglected Tropical Diseases. New England Journal Of Medicine, Vol. 357(10), 1018-1027.

Jin, H., Ryu, K., Lee, D., Vonghachack, Y., Choi, M.-H., Hong, S.-T. and Song, H. B., 2021, Prevalence and Risk Factors of Intestinal Helminthiasis in Remote Mountainous Villages of Northern Lao PDR: A Cross-Sectional Study. The Korean Journal of Parasitology, Vol. 59(2), 131-138. DOI:10.3347/kjp.2021.59.2.131.

Jongsuksuntigul, P. and Imsomboon, T., 2003, Opisthorchiasis Control in Thailand. Acta Tropica, Vol. 88(3), 229-232.

Kattula, D., Sarkar, R., Ajjampur, S. S. R., Minz, S., Levecke, B., Muliyil, J. and Kang, G., 2014, Prevalence \& Risk Factors for Soil Transmitted Helminth Infection among School Children in South India. The Indian Journal of Medical Research, Vol. 139(1), 76-82.

Kounnavong, S., Vonglokham, M., Houamboun, K., Odermatt, P. and Boupha, B., 2011, Soiltransmitted Helminth Infections and Risk Factors in Preschool Children in Southern Rural Lao People's Democratic Republic. Transactions of the Royal Society of Tropical Medicine and Hygiene, Vol. 105(3), 160-166. doi:10.1016/j.trstmh.2010.11.011.

Nasr, N. A., Al-Mekhlafi, H. M., Ahmed, A., Roslan, M. A. and Bulgiba, A., 2013, Towards an Effective Control Programme of SoilTransmitted Helminth Infections among Orang Asli in Rural Malaysia. Part 2: Knowledge, Attitude, And Practices. Parasites \& Vectors, Vol. 6(1), 1-12. 
Karnkawinpong, O., Wongsaroj, T. and Nakai, W., 2010, Situation Helminthes and Intestinal Protozoa in Marginalized Groups (Tribes) of Thailand. Bureau of General Communicable Disease, Department of Disease Control, Ministry of Public Health. 2010. Available at http://haigcd. ddc.moph.go.th., accessed.

Shang, Y., Tang, L.-H., Zhou, S.-S., Chen, Y.-D., Yang, Y.-C. and Lin, S.-X., 2010, Stunting and Soil-Transmitted-Helminth Infections among School-Age Pupils in Rural Areas of Southern China. Parasites \& Vectors, Vol. 3(1), 1-6.

Thinkhamrop, K., Suwannatrai, A. T., Chamadol, N., Khuntikeo, N., Thinkhamrop, B., Sarakarn, P. and Kelly, M., 2020, Spatial Analysis of Hepatobiliary Abnormalities in a Population at High-Risk of Cholangiocarcinoma in Thailand. Scientific Reports, Vol. 10(1), 1-10.

Wang, X., Zhang, L., Luo, R., Wang, G., Chen, Y., Medina, A. and Smith, D. S., 2012, Soiltransmitted Helminth Infections and Correlated Risk Factors in Preschool and School-Aged Children in Rural Southwest China. https://doi.org/10.1371/journal.pone.0045939.

Wang, Y.-C., Grundy-Warr, C., Namsanor, J., Kenney-Lazar, M., Tang, C. J. Y., Goh, L. Y. W. and Khuntikeo, N., 2021, Masculinity and Misinformation: Social Dynamics of Liver Fluke Infection Risk in Thailand. Parasitology International, Vol. 84, https://doi.org/10.1016/j.parint.2021.102382.
World Health Organization, 2009, Soil-transmitted Helminthiases: Estimates of the Number of Children Needing Preventive Chemotherapy and Number Treated. Geneva. 1-10.

World Health Organization, 2011, Helminth control In School-Age Children a Guide for Managers of Control Programmes Second Edition. 1-75. https://apps.who.int/iris/handle/10665/44671.

Yajima, A., Jouquet, P., Trung, D. D., Cam, T. D. T., Cong, D. T., Orange, D. and Montresor, A., 2009, High Latrine Coverage is not Reducing the Prevalence of Soil-Transmitted Helminthiasis in Hoa Binh Province, Vietnam. Transactions of the Royal Society of Tropical Medicine and Hygiene, Vol. 103(3), 237-241.

Ziegelbauer, K., Speich, B., Mäusezahl, D., Bos, R., Keiser, J. and Utzinger, J., 2012, Effect of Sanitation on Soil-Transmitted Helminth Infection: Systematic Review and MetaAnalysis. PLOS Medicine, Vol. 9(1), e1001162. doi:10.1371/journal.pmed.1001162. 